\title{
A BUSCA PELA QUALIDADE NA EDUCAÇÃO INFANTIL PÚBLICA BRASILEIRA SOB O ENFOQUE DA DIVERSIDADE E DA INCLUSÃO
}

\author{
Célia Gomez Sardinha da Silva ${ }^{1}$ \\ Edna Maria Querido de Oliveira Chamon ${ }^{2}$ \\ Pétala Gonçalves Lacerda ${ }^{3}$ \\ Nilsen Aparecida Vieira Marcondes ${ }^{4}$
}

Resumo: Muito se tem discutido a respeito da Educação Infantil, primeira etapa da Educação Básica, que corresponde ao atendimento institucionalizado da criança de zero a cinco anos de idade. De modo geral, a esfera para o debate é vasta e fértil, consideradas as diferentes facetas de um tema amplo. Diante disso, objetiva-se, com este estudo teórico, básico, qualitativo e exploratório, caracterizado como pesquisa bibliográfica, refletir sobre a busca pela qualidade na educação infantil pública brasileira sob o enfoque da diversidade e da inclusão, adensando a literatura disponível sobre o assunto. Conclui-se que, a caracterização do percurso histórico da institucionalização do atendimento à criança pequena no Brasil, da relação família-escola e das diversidades regionais constituem-se como elementos relevantes quando se intenciona analisar a qualidade de ensino na área da Educação Infantil.

Palavras-chave: Educação Infantil Brasileira; Qualidade; Diversidade. Inclusão.

\footnotetext{
${ }^{1}$ Programa de Pós-graduação em Educação e Desenvolvimento Humano (PPGEDH)/Universidade de Taubaté (UNITAU), Brasil. E-mail: E-mail: cgsds@uol.com.br.

2 Programa de Pós-graduação em Educação e Desenvolvimento Humano (PPGEDH)/Universidade de Taubaté (UNITAU), Brasil. E-mail: edna.chamon@gmail.com.

${ }_{3}^{3}$ Programa de Pós-graduação em Educação e Desenvolvimento Humano (PPGEDH)/Universidade de Taubaté (UNITAU), Brasil. E-mail: petala.lacerda@gmail.com.

${ }^{4}$ Programa de Pós-graduação em Educação e Desenvolvimento Humano (PPGEDH)/Universidade de Taubaté (UNITAU), Brasil. E-mail: nilsenmarcondes@gmail.com.
} 